\title{
Special Issue Introduction
}

\section{Nordic Legal Education: A Situated Gothenburg Perspective}

\author{
Sari Kouvo ${ }^{1}$ \\ Department of Law, University of Gothenburg, Sweden \\ Erik Björling ${ }^{2}$ \\ Department of Law, University of Gothenburg, Sweden
}

Legal education at the University of Gothenburg, as well as legal education in Sweden and the Nordic countries, is largely designed and perceived as a professional qualification. The bulk of the courses are implicitly or explicitly developed with legal practitioners in core legal functions in mind. That is, the study programme prepares students for work as civil servants, lawyers in different fields, judges and prosecutors. Most of the courses provide future legal practitioners with knowledge and skills in core legal fields, including public law, criminal law, civil law and criminal and civil procedure law. The LLM programmes usually include some more theoretical and interdisciplinary themes that seek to ensure that students receive a solid university education and can reflect critically on the law and its role in society. Inherent in the LLM programme therefore is a balance (or a conflict) between concrete (professional) training and general (scholarly) competence. Inherent in the theoretical and critical reflection is to provide students with the tools to analyse the role of lawyers and the law in relation to changing social challenges.

\footnotetext{
${ }^{1}$ Address: Sari Kouvo, Department of Law, School of Business, Economics and Law, University of Gothenburg, Box 650, SE-405 30 Gothenburg, Sweden. E-mail: sari.kouvo@law.gu.se

${ }^{2}$ Address: Erik Björling, Department of Law, School of Business, Economics and Law, University of Gothenburg, Box 650, SE-405 30 Gothenburg, Sweden. E-mail: erik.bjorling@law.gu.se
} 
For a few years, the Department of Law at the University of Gothenburg has been attempting to reform the legal education that it provides. The reflections about reform were prompted by changes at the Department of Law and the growing number of students who benefit from our education. Over the past decade, the Department of Law has expanded from a staff size (administrative staff and doctoral students included) of about 50 to around 100 today, and expanded from about 150 students annually to 250 students annually. The expansion has affected both the students' learning environment and brought new challenges for the teaching staff. The students move through the LLM programme in bigger student groups, get fewer seminar opportunities and most likely less individual time with their lecturers. Dealing with groups of more than 200 students demands a different level of planning, administration and organisation from the teaching staff and thus results in fewer opportunities for trying out new ideas and off-the-cuff creativity. Due to this expansion, the effort to reform the LLM programme has largely come to focus on how to ensure that students can learn and progress in a healthy academic environment while at the same time making the most efficient use of the existing teaching resources.

The thematic research group on jurisprudence, one of seven thematic research groups at the Department of Law, used the reform process to reflect not only on how students learn, but also on what they learn, including the balance between different legal disciplines and between concrete (professional) training and general (scholarly) competence. The group has also reflected on what students should learn, including the normative guidance provided by the Swedish government for higher education in general and legal education in particular, and focused on social and increasingly global challenges. None of these questions are easy. They are all fundamentally tied to approaches to law, higher education and the idea of academic independence.

The efforts to reform the LLM programme have been put on hold due to the COVID-19 pandemic. Or rather we - like most other higher education providers - have been forced to transform the delivery of our education at a pace and in ways that we never intended. We have all had to invent and put in place distance and online learning environments virtually overnight, while also trying to make sure that teaching staff and students cope and 
ideally thrive. Before the pandemic, none of us, when thinking about reforming the LLM programme, expected that we would need to so quickly deal with such profound changes in the context and the ways in which our LLM programme is provided. As we are moving into the second year of the pandemic, we also do not know how the global spread of a virus and the possible changes in our societies, politics or institutions that has prompted or is driving, will affect the legal profession that we are preparing our students for. This makes the questions pondered by the research group on jurisprudence that are at the heart of this special issue even more pressing. They are:

- How does and possibly should legal education balance a focus on professional training and introducing students to scholarly knowledge production and (legal) theory?

- What does it mean to be a 'good' lawyer? Is it the same or different from being a good citizen?

- How does location matter for teaching and acquiring knowledge about the law? Do we and should we equip our law students to understand and engage with the global challenges of today?

- How can the LLM programme be used to encourage students to engage with society and pressing social issues, including increasing inequalities?

- How can intersectional and norm-critical perspectives be integrated into legal education? Will it change how students - and teachers - view the law and society?

In this special issue, these questions are explored from the perspective of the LLM programme at the University of Gothenburg. The special issue is an exercise in digging where you stand, making use of your own experiences and the possibilities and limits of your own context in scholarly knowledge production. However, the special issue uses other LLM programmes in the Nordic countries for perspective. When plans started for this special issue in 2018, material was collected (study programmes, course syllabuses, reading lists, etc.) from 17 Nordic LLM programmes (see Annex). The material provides a bird's eye view or a snapshot of what the syllabuses for LLM programmes looked like in 2018. 
Before having a closer look at the articles in this special issue, a few words should be said about the LLM programme at the University of Gothenburg and especially its approach to legal theory or jurisprudence, and legal education that seeks to understand - and possibly respond to - global and societal challenges. The Department of Law has also historically had a broad and inclusive approach to the discipline of Legal Theory. Questions about legal thinking and its concepts, the nature of law and its relationships to other normative and governance frameworks are, of course, central for the discipline. Such studies can be done on a purely theoretical level or linked to a specific area of law. Furthermore, legal argumentation and methodological questions as well as the relationship between different legal systems and legal cultures are studied. But Legal Theory includes even more. Questions about how the legal sphere relates to and interacts with politics, morals, society, economics and culture are also central. Law is interpreted, used and developed by different actors in specific contexts; how these contexts can be understood and how changes appear are key issues. This includes studies concerning power structures, gender, ethnicity, and more. This means that Legal Theory at the University of Gothenburg includes what is internationally referred to as jurisprudence, legal philosophy, legal theory, critical legal theory, law in context, and law and society and is characterized by theorising the law by placing it in different contexts and visualising the relational aspects of the law. Examples of theories used and developed within the discipline at the University of Gothenburg are liberal theories; critical theories such as feminist, gender and postcolonial theories; theories of law and literature; socio-legal theories; and social planning theories.

It is through the study of jurisprudence, but also through critical and broader reflection when teaching other core legal disciplines that the law students at the University of Gothenburg are confronted with and encouraged to engage with social and increasingly global challenges. For the purpose of this special issue, we use a broad definition of social challenges. As noted above, it includes both the challenges that the University and/or its legal education is encouraged to engage with through the political guidance provided by government policy. However, the social challenges also include issues that are high on the political agenda or that legal and governance structures are forced to tackle, including for example 
migration, climate change/environmental concerns, social and economic inequality (poverty), artificial intelligence and a rise in conflict at national and international levels. For an academic institution that takes research and teaching tasks seriously, it is obviously important to ensure in-depth and critical reflection around what we are asked to reflect, what we choose to reflect and what we may unintentionally reflect.

This special issue includes five articles that in different ways engage with the above-mentioned questions and focus on both the role of theory in legal education and the role of legal education in helping students understand and engage with the global and social challenges of today.

The introductory article by Erik Björling and Eva-Maria Svensson entitled The Role of Legal Theory in Legal Education: A Reflection on Professional and Scholarly Ideals in Nordic Legal Education focuses on the development of legal theory as one of the compulsory subjects in the LLM programme at the University of Gothenburg and also across the Nordic LLM programmes. Through its focus on legal theory in legal education, the article problematizes issues around legal education as a 'professional' and/or 'scholarly' education, as well as the relevance of critical reflection on the law and its role in politics and society.

Sari Kouvo's article Teaching International Law in Times of Change and Crises focuses on how location matters for how international law is taught and how being blind about the influence of location also may make us blind to how geopolitics affects the day-to-day realities of international law. The article is centred around a role play exercise about international law and peace negotiations in Afghanistan. The role play provides opportunities for the students to represent key actors in the peace process, including the Afghan and US governments, the United Nations and the Taliban. Lessons learned from the role play are that the further from 'government' and 'Western' perspectives students are encouraged to tread, the more eyeopening and transformative the case study is. The role play leads Kouvo to discuss the importance of providing students with opportunities to move outside the peace and stability centred narrative of international law and to become attentive to all the imperfect ways in which international law operates in a polarized and conflict-prone world.

The last two articles shift the focus back to the present-day LLM programme at the University of Gothenburg and more broadly to questions 
about how legal education addresses difference, diversity, and the growing social and economic inequalities in our societies.

Erik Mägi's article Lessons from a Study of Diversity and Equality in Legal Education: Methodology, Findings and Relevance for Teaching takes its starting point in a norm-critical and intersectional analysis of the LLM programme at the University of Gothenburg. In 2015, Feministiska Juriststudenter (the student association for feminist law students) conducted an informal assessment of the examples and assignments used in one of the compulsory law courses. The assessment showed a considerable over-representation of men and an almost exclusive representation of people of Nordic origin in the examples and assignments. This assessment prompted the Department of Law to conduct a normcritical and intersectional analysis of all the examples and assignments in compulsory law courses. A norm-critical perspective seeks to critically examine what is defined as norm and what is defined as exception, and how the social divisions and hierarchies are created by processes of inclusion and exclusion. An intersectional perspective again seems to unpack traditional ways of categorising (that have also influenced nondiscrimination law) and show the complex interaction between social relationships and power. Together, the two perspectives provide a useful tool for analysing how different groups of people are represented in examples and assignments. The analysis done by the Department of Law showed that men, Nordic people, adults and people from the middle and upper class/socioeconomic status were overrepresented compared to Swedish society as a whole. The study resulted in important discussions at the Department of Law about whether representations matter and if so, what should be done. Mägi's article seeks to present the theoretical thinking behind the norm-critical study, the study itself, and possible ways of dealing with its recommendations.

Sara Stendahl's, Otto Swedrup's and Karin Åberg's article The Gothenburg Law Clinic and the Use of Threshold Concepts in Clinical Legal Education focuses on the law clinic that since 2014 has been one of the elective courses in the LLM programme at the University of Gothenburg. The article examines the core pedagogical elements of the course and within legal clinics more broadly, i.e., anchoring teaching in grassroots legal realities as a means to enhance reflection on the complex 
interplay between black-letter law and law in practices, that is, the effort to focus legal education on "real problems, faced by real people in real society". The legal clinic was part of the network of local non-profit, mainly non-governmental, organisations working in the segregated city of Gothenburg. The authors of the article, who are also the persons responsible for the legal clinic, argue that the lawyers who we educate today need to be prepared to meet resistance of a new kind. Given the strong and growing interest in legal clinics in legal education in other European countries, this seems to be low-hanging fruit for a reform agenda. If a strong theoretical component were to be added, there could be yet another Nordic model in sight.

This special issue concludes with a brief comment about the Nordic legal education based on the material collected from the Nordic LLM programmes in 2018 by Miran Kakaee. The collection of the material and especially the effort to put together the Annex provided an opportunity for the editors of this special issue and Kakaee to critically reflect on the delineation between and weight given to different legal disciplines in legal education at the University of Gothenburg, as well as the similarities and differences between the different Nordic LLM programmes.

\section{Notes on contributors}

Sari Kouvo is an associate professor in international law at the Department of Law at the University of Gothenburg. Kouvo's previous engagements include co-director of the Afghanistan Analysts Network, a field-based policy research organisation focused on politics and security in Afghanistan, policy officer at the European External Action Service, head of program at the International Centre for Transitional Justice, researcher at Amnesty International and special adviser to the EU Special Representative for Afghanistan. Kouvo has taught at Kent University, Vrije Universitet Brussels and Birkbeck University, and she has held visiting fellowships at the Australian National University, Åbo Academy, NATO Defense College and Kent and Keele universities. She has acted as a consultant for the Swedish International Development Agency, the Swedish Afghanistan Committee, UN Women and the European Peace Liaison Office. She has published widely on international law and Afghanistan-related topics. 
Erik Björling is a senior lecturer in procedural law at the Department of Law at the University of Gothenburg. He has worked as a teacher and researcher since 2011 within the fields of legal theory and procedural law. Björling's research is primarily focused on civil procedure, in particular the socio-legal and theoretical aspects of dispute resolution. In his thesis, he develops methodological concepts that contribute to the understanding and critique of legal argumentation in court proceedings. He is currently working on a project concerning digital conflict resolution, especially in light of the European framework for "Online Dispute Resolution”. 